\title{
Predictors of Congestive Heart Failure Mortality in Elderly People From the General Population
}

\author{
The CArdiovascular STudy in the ELderly (CASTEL) \\ Alberto MAZZA, ${ }^{1} \mathrm{MD}$, PhD, Valérie TiKhONOFF, ${ }^{1} \mathrm{MD}$, Edoardo CAsiglia, ${ }^{1} \mathrm{MD}$, \\ and Achille Cesare PEssina, ${ }^{1} \mathrm{MD}, \mathrm{PhD}$
}

\begin{abstract}
SUMMARY
Congestive heart failure (CHF) is highly prevalent in the elderly. The aim of this study was to identify the predictors of CHF mortality in patients over 65 years of age who were free of CHF at initial screening. A total of 3,282 elderly subjects were recruited in a population-based frame and 12-year events were recorded. Continuous items were divided into tertiles and for each tertile adjusted the relative risk (RR) with $95 \%$ confidence intervals $(\mathrm{CI})$ was derived in both genders from multivariate Cox analysis of CHF mortality.

Age $\geq 72$ years ([RR]: $2.24 ; 95 \%$ CI $1.56-3.24$ ), male gender ([RR]: $1.4 ; 95 \% \mathrm{CI}$ $1.02-1.76$ ), clinical history of coronary artery disease ([RR]: 1.25 ; 95\% CI $1.02-1.76$ ), pulse pressure $\geq 79 \mathrm{mmHg}$ ([RR]: $1.33 ; 95 \%$ CI $1.03-1.87$ ), heart rate $\geq 81 \mathrm{bpm}$ ([RR]: 1.32; 95\% CI $1.10-1.96$ ), atrial fibrillation ([RR]: 1.82 ; 95\% CI $1.18-2.81$ ), left ventricular hypertrophy ([RR]: 1.42; 95\% CI $1.01-2.02$ ), diabetes ([RR]: $1.35 ; 95 \%$ CI 1.02 - 1.78), vital capacity $\leq 81 \%$ of the theoretical value ([RR]: $2.50 ; 95 \%$ CI $1.88-3.32$ ), forced expiratory volume in 1 second $\leq 72 \%$ of the theoretical value ([RR]: $2.02 ; 95 \%$ CI $1.55-2.72$ ) and serum sodium level $\leq 139 \mathrm{mmol} / \mathrm{L}$ ([RR]: $1.95 ; 95 \%$ CI $1.44-2.63$ ) predicted CHF mortality.

This model is able to identify elderly people at increased risk of death from CHF. (Int Heart J 2005; 46: 419-431)
\end{abstract}

Key words: Congestive heart failure, Mortality, Epidemiology, Relative risk, Population, Elderly

IN recent decades, congestive heart failure $(\mathrm{CHF})$ has gradually become one of the most prevalent cardiovascular disorders in Western societies, particularly in the elderly. ${ }^{1)}$ More than $75 \%$ of patients with CHF are older than 65 years ${ }^{2)}$ and in this age class CHF is one of the most important causes of death and chronic disability. ${ }^{3)}$ This is due to the progressive ageing of the population, ${ }^{4}$ as well as to the decrease in mortality from acute coronary events. ${ }^{5)}$ It is, therefore, not surprising

\footnotetext{
From the ${ }^{1}$ Department of Clinical and Experimental Medicine, Laboratory of Epidemiology, University of Padova, Padova Italy.

Address for correspondence: Alberto Mazza, MD, Department of Clinical and Experimental Medicine, Via Giustiniani, 235128 Padova, Italy.

Received for publication August 12, 2004

Revised and accepted January 6, 2004. 
that in the last two decades many papers have been devoted to the epidemiology, physiopathology, and etiology of $\mathrm{CHF}^{3,4,6)}$

The most important data concerning the impact of $\mathrm{CHF}$ on public health derive from pharmacological trials, ${ }^{7)}$ hospital records, ${ }^{8)}$ and general practice studies, ${ }^{9)}$ and involve mainly subjects aged less than 65 years. On the contrary, only a limited number of studies have included elderly people from the general population. ${ }^{6,10-12)}$ This is particularly true in Europe, where only 1 population-based study on CHF is available. ${ }^{13)}$

As a consequence, the independent predictors of CHF in this age class are not well defined.

In this paper, the parameters able to predict CHF mortality have been identified in 3,282 subjects aged over 65 years of age from North-East Italy, taking part in the CArdiovacular STudy in the ELderly (CASTEL), a prospective population-based study aimed at identifying the cardiovascular risk factors and, more in general, the predictors of mortality in elderly people. The 12-year results are described herein.

\section{Methods}

General protocol: The CASTEL enrolled 3,282 subjects (1,281 men and 2,001 women) aged 65 years or over, representing $73 \%$ of the elderly subjects from the Northern Italian towns of Castelfranco and Chioggia (Veneto region). An initial screening and a follow-up including mortality over a period of 12 years were scheduled. ${ }^{14)}$

During the initial screening as well as at the end of follow-up, heart rate and sphygmomanometric supine blood pressure were measured in triplicate at 15-min intervals. This last procedure was repeated 3 times at 1-month intervals and the average of the last 2 of the 9 measurements was taken into consideration. Pulse pressure was the difference between systolic and diastolic blood pressure. Since $72 \%$ of the men and $75 \%$ of the women were on antihypertensive medication, "antihypertensive therapy" as a dichotomic covariate was included in the multivariate Cox analysis in order to adjust the results. Historical data were recorded by means of a questionnaire.

Body mass index (BMI, in $\mathrm{kg} / \mathrm{m}^{2}$ ) was calculated as the weight/squared height ratio. All subjects were screened for albuminuria with a dipstick using a random morning urine sample. Subjects were classified into current $(\geq 1$ cigarette daily) smokers, never smoked, or ex-smokers; the latter had given up the smoking habit for at least one year prior to the screening. The subjects were divided into drinkers ( $\geq 50 \mathrm{~mL}$ daily) and nondrinkers according to their consumption of alco- 
Table I. Cut-off Values and Diagnostic Criteria of Disease

\begin{tabular}{ll}
\hline Condition or disease & Cut-off and criteria \\
\hline Arterial hypertension & Systolic blood pressure $\geq 140$ or diastolic $\geq 90 \mathrm{mmHg}$ or \\
treated & Blood glucose $\geq 126 \mathrm{mg} / \mathrm{dL}$ or antidiabetic treatment \\
Diabetes & Total cholesterol $>200 \mathrm{mg} / \mathrm{dL}$ \\
Hypercholesterolemia & Triglycerides $>150 \mathrm{mg} / \mathrm{dL}$ \\
Hypertriglyceridemia & Minnesota code 3.1 or 3.3 \\
Left ventricular hypertrophy & Minnesota code 8.3 \\
Atrial fibrillation & Minnesota code $1.1,1.2$ or 1.3 (being absent 6.4 .1$)$ \\
Historical myocardial infarction & or positive history in hospital records or akinesia/dyskinesia \\
& at time of echocardiogram or angiography \\
& Typical chest pain with Minnesota code 4.1, \\
Historical angina pectoris & $4.2,5.1$ or 5.2 (being absent $6.4 .1,7.1 .1,7.2 .1,7.4)$ \\
& Cerebrovascular episode with permanent outcomes \\
History of stroke & (motor or sensory loss, aphasia, dysarthria) \\
Overweight & BMI $>25 \mathrm{~kg} / \mathrm{m}^{2}$ in both genders \\
Proteinuria & $>200 \mathrm{mg} / \mathrm{L}$ \\
\hline
\end{tabular}

hol. Forced expiratory volume in 1 second $\left(\mathrm{FEV}_{1}\right)$ and vital capacity $(\mathrm{VC})$ were measured by a spirometer, and reference values individually calculated. ${ }^{15)}$

Electrocardiograms (ECG) were analysed on the basis of the Minnesota code. ${ }^{16)}$ Coronary artery disease (CAD) at entry was defined as a history of myocardial infarction and/or angina pectoris. Cut-off values for categorical items and diagnostic criteria of disease are summarised in Table I.

Definition of CHF: Subjects with a self-reported diagnosis of CHF underwent a careful clinical examination by a physician. According to the guidelines of the European Society of Cardiology, ${ }^{17)}$ subjects experiencing breathlessness, ankle swelling fatigue, raised venous pressure, and a third heart sound were considered to have CHF. A diagnosis of CHF by a physician was then followed by review of the participant's medical records. For the present paper, 329 subjects (116 men and 213 women, respectively) having a history of CHF at initial screening, were excluded from the analysis of data.

Mortality: Annual mortality was monitored by examining government records and the causes of death were verified by referring to hospital, retirement home, and/or physician records.

All records were coded according to ICD-9-CM by a specially trained research physician supervised by another more experienced colleague, to accurately determine the cause of death. If necessary, a third physician was contacted. No information about mortality was lost to follow-up. The codes for CHF were 398.91, 402.11, 402.91, 404.11, 404.13, 404.91, 404.93, 428.0-428.9. 
Statistical analysis: Cumulative survival curves of CHF mortality were generated with the life-table method and compared with the Mantel-Haenzels approach. Analysis of variance was used for comparing groups, and Pearson's $\chi^{2}$ test was used to compare the prevalence of categorical variables.

Continuous variables, expressed as mean \pm standard deviation (SD), were divided into tertiles. For each tertile the relative risk (RR) with $95 \%$ confidence intervals (95\% CI) adjusted for confounders was derived from logistic regression ${ }^{18,19)}$ for CHF mortality. Stepwise Cox proportional hazard models with a $P$ value of 0.05 were used to identify risk factors for CHF mortality in multivariate analysis excluding subjects having $\mathrm{CHF}$ at baseline. The models included as covariates demographic items (age, gender), historical disease (history of CAD, stroke or transient ischaemic attack and intermittent claudication, chronic obstructive pulmonary disease [COPD], hypertension, and diabetes), laboratory (blood lipids and proteinuria) and clinical examination measures (BMI, resting heart rate, murmurs at the neck), ECG abnormalities (atrial fibrillation and left ventricular hypertrophy $[\mathrm{LVH}])$, and spirometry $\left(\mathrm{VC}\right.$ and $\left.\mathrm{FEV}_{1}\right)$. Statistics were analyzed using a BioMedical Data Processing (BMPD) package (Cork, Ireland) version 6.0 .

The study lasted 12 years and was carried out in accordance with the Declaration of Helsinki of the World Medical Association and approved by the local Ethics Committee. The procedures followed were in accordance with institutional guidelines.

\section{RESULTS}

General characteristics: Mean age was $73.8 \pm 5.3$ years (range, 65 to 91) overall, $73.0 \pm 4.8$ in the 1195 men, and $74.0 \pm 5.5$ in the 1758 women $(P<0.0001)$. Men showed higher mean values of uric acid and serum creatinine, as well as a greater prevalence of proteinuria, than women (Table II). Meanwhile, age, heart rate, total cholesterol, high density lipoprotein cholesterol and low density lipoprotein cholesterol, $\mathrm{VC}$, and $\mathrm{FEV}_{1}$ as well as the prevalence of arterial hypertension were higher in the women than in the men.

Longitudinal study: Univariate analysis of outcome. A total of 3,282 subjects were enrolled at initial screening, and 329 of those having CHF were excluded from the analysis of data. At the end of the follow-up period, 1,372 subjects had died and 1,581 were alive (overall mortality rate, $46.4 \%, 56.9 \%$ in men and $42.4 \%$ in women; $P<0.0001$ ). No information about mortality was lost to the follow-up.

In the CASTEL study, CHF mortality was more prevalent in men than in women (Figure 1). 
Table II. Baseline Characteristics of the 2953 Elderly Subjects From the CASTEL Without CHF at Initial Screening Adjusted for Age and Gender

\begin{tabular}{lccc}
\hline \multicolumn{1}{c}{ Characteristic } & $\begin{array}{c}\text { Men } \\
(n=1195)\end{array}$ & $\begin{array}{c}\text { Women } \\
(n=1758)\end{array}$ & $\begin{array}{c}P \text {-value } \\
\text { between groups }\end{array}$ \\
\hline Age (years) & $73.0 \pm 4.8$ & $74.0 \pm 5.5$ & $<0.002$ \\
Pulse pressure (mmHg) & $69.2 \pm 19.0$ & $72.4 \pm 19.5$ & $<0.001$ \\
Heart rate (bpm) & $73.3 \pm 11.4$ & $77.5 \pm 11.3$ & $<0.002$ \\
Uric acid (mmol/L) & $0.33 \pm 0.08$ & $0.29 \pm 0.08$ & $<0.002$ \\
Creatinine (mmol/L) & $88.4 \pm 0.3$ & $79.5 \pm 0.4$ & $<0.002$ \\
Total cholesterol $(\mathrm{mmol} / \mathrm{L})$ & $5.4 \pm 1.1$ & $5.9 \pm 1.1$ & $<0.0001$ \\
HDL-cholesterol $(\mathrm{mmol} / \mathrm{L})$ & $1.4 \pm 0.4$ & $1.6 \pm 0.4$ & $<0.0001$ \\
LDL-cholesterol $(\mathrm{mmol} / \mathrm{L})$ & $3.3 \pm 0.97$ & $3.6 \pm 1.0$ & $<0.002$ \\
Triglycerides $(\mathrm{mmol} / \mathrm{L})$ & $1.6 \pm 0.9$ & $1.7 \pm 0.9$ & $<0.0001$ \\
VC $(\%$ of theoretical) & $90.3 \pm 21.5$ & $94.2 \pm 21.0$ & $<0.002$ \\
FEV1 $(\%$ of theoretical) & $80.5 \pm 23.7$ & $85.3 \pm 25.9$ & $<0.0001$ \\
Hypertension $(\%)$ & 51.7 & 58.2 & $<0.0001$ \\
Diabetes $(\%)$ & 6.8 & 8.8 & $<0.0001$ \\
Proteinuria $(\%)$ & 12.1 & 9.5 & \\
\hline BMI, systolic and & & & \\
\hline
\end{tabular}

BMI, systolic and diastolic blood pressure, serum sodium, smoking habits and alcohol consumption, historical CAD, stroke or transient ischemic attack, atrial fibrillation, and LVH were also tested but there were no significant differences between the groups. $\mathrm{HDL}=$ high-density lipoprotein $\mathrm{LDL}=$ low-density lipoprotein; $\mathrm{VC}=$ vital capacity; $\mathrm{FEV}_{1}=$ forced expiratory volume in 1 second.

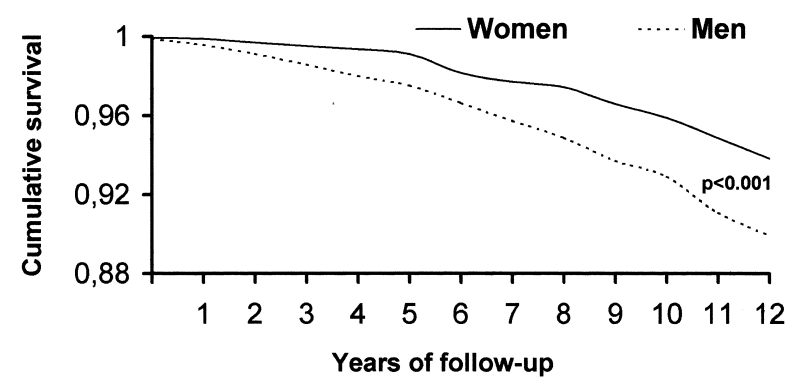

Figure. Kaplan-Meier survival curves for fatal congestive heart failure in 1,758 women $(-)$ and 1,195 men $(\cdots$.$) from the CASTEL.$

Multivariate analysis for CHF mortality. In the whole population, 12 parameters (age, male gender, historical CAD, atrial fibrillation, $\mathrm{FEV}_{1}$ and $\mathrm{VC}, \mathrm{LVH}$, pulse pressure, diabetes, heart rate, and serum sodium level) turned out to be multivariate independent predictors of CHF mortality (Table III). 
Table III. Results of the Multivariate Cox Equation for Cardiac Heart Failure Mortality in the CASTEL

\begin{tabular}{lcccc}
\hline & $\chi^{2}$ enter & $\chi^{2}$ remove & Improvement $\chi^{2}$ & $P$-value \\
\hline Age & 55.45 & 18.54 & 45.78 & $<0.0001$ \\
Historical CAD & 50.43 & 29.32 & 35.45 & $<0.01$ \\
Vital capacity & 49.01 & 27.81 & 31.42 & $<0.0001$ \\
FEV $_{1}$ & 46.61 & 18.22 & 22.88 & $<0.0001$ \\
LVH & 3.97 & 3.78 & 7.69 & $<0.01$ \\
Male gender & 8.85 & 2.49 & 6.83 & $<0.01$ \\
Atrial fibrillation & 15.64 & 6.47 & 6.33 & $<0.001$ \\
Diabetes & 9.80 & 3.69 & 5.67 & $<0.01$ \\
Pulse pressure & 7.10 & 3.03 & 5.12 & $<0.04$ \\
Serum sodium & 9.26 & 3.76 & 5.02 & $<0.0001$ \\
Heart rate & 9.65 & 5.27 & 4.87 & $<0.04$ \\
Overweight & 1.03 & - & - & - \\
Antihypertensive therapy & 1.36 & - & - & - \\
Uric acid & 7.10 & - & - & - \\
Hypercholesterolemia & 6.77 & - & - & - \\
Hypertriglyceridemia & 4.67 & - & - & - \\
Historical stroke & 8.03 & - & - & - \\
Proteinuria & 4.64 & - & - & - \\
Cigarette smoking & 1.19 & - & - & \\
\hline CAD & & & & - \\
\hline
\end{tabular}

$\mathrm{CAD}=$ coronary artery disease $\mathrm{FEV}_{1}=$ forced expiratory volume in 1 second; $\mathrm{LVH}=$ left ventricular hypertrophy.

Age was the main risk factor of CHF mortality; the risk of dying of $\mathrm{CHF}$ progressively increased from the first to the second ([RR] 2.24; 95\% CI, 1.56 to 3.24 ) to the third tertile of age ([RR] 4.63; 95\% CI, 3.27 to 6.56).

Men were at a disadvantage compared to women ([RR]: 1.4; 95\% CI, 1.02 to 1.76 ) until 75 years of age. In the last age class ( $\geq 76$ years), CHF mortality did not differ between the two genders (14.1 versus $14.5 \%$, NS).

Historical CAD ([RR]: 1.25 ; $95 \%$ CI, 1.02 to 1.76 ) resulted to be an independent risk factors for CHF mortality both in men and women (insignificant difference between genders).

CHF mortality was comparable in normotensive and hypertensive subjects (10.2 versus $9.2 \%$, respectively, NS). Nevertheless, CHF mortality progressively increased from the first to the last tertile of pulse pressure $(8.0,8.6$, and $10.6 \%$, respectively; $P<0.04$ versus the last versus first). Based on multivariate analysis, pulse pressure was found to be an independent predictor of mortality, with the RR sharply increasing when pulse pressure was $\geq 79 \mathrm{mmHg}$ (Table IV). CHF mortality showed no relation with either systolic or diastolic blood pressure. 
Table IV. Relative Risk (RR) of CHF Mortality in the CASTEL

\begin{tabular}{|c|c|c|c|}
\hline Parameter & Mortality & $\mathrm{RR}$ & $95 \% \mathrm{CI}$ \\
\hline \multicolumn{4}{|l|}{ Age (years) } \\
\hline $1^{\text {st }}$ tertile $(65-71)$ & $4.2(\%)$ & 1 & Reference \\
\hline $2^{\text {nd }}$ tertile $(72-75)$ & $8.6(\%)$ & 2.24 & $1.56-3.24 \dagger$ \\
\hline $3^{\text {rd }}$ tertile $(\geq 76)$ & $14.4(\%)$ & 4.63 & $3.27-6.56^{*}$ \\
\hline \multicolumn{4}{|l|}{ Gender } \\
\hline Male & $9.6(\%)$ & 1.4 & $1.09-1.80 \%$ \\
\hline Female & $8.5(\%)$ & 1 & Reference \\
\hline \multicolumn{4}{|c|}{ History of coronary artery disease } \\
\hline No & $8.5(\%)$ & 1 & Reference \\
\hline Yes & $13.1(\%)$ & 1.25 & $1.02-1.76 \neq$ \\
\hline \multicolumn{4}{|l|}{ Pulse pressure (mmHg) } \\
\hline $1^{\text {st }}$ tertile $(\leq 60)$ & $8(\%)$ & 1 & Reference \\
\hline $2^{\text {nd }}$ tertile $(61-78)$ & $8.6(\%)$ & 1.03 & $0.76-1.40$ \\
\hline $3^{\text {rd }}$ tertile $(\geq 79)$ & $10.6(\%)$ & 1.33 & 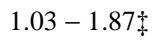 \\
\hline \multicolumn{4}{|l|}{ Heart rate (bpm) } \\
\hline $1^{\text {st }}$ tertile $(\leq 71)$ & $8(\%)$ & 1 & Reference \\
\hline $2^{\text {nd }}$ tertile $(72-80)$ & $8.1(\%)$ & 1.02 & $0.75-1.39$ \\
\hline $3^{\text {rd }}$ tertile $(\geq 81)$ & $11.2(\%)$ & 1.32 & $1.10-1.96 \%$ \\
\hline \multicolumn{4}{|c|}{ Vital capacity ( $\%$ of theoretical value) } \\
\hline $1^{\text {st }}$ tertile $(\leq 81)$ & $15.7(\%)$ & 2.50 & $1.88-3.32 *$ \\
\hline $2^{\text {nd }}$ tertile $(82-100)$ & $8.4(\%)$ & 1.45 & $0.88-1.63$ \\
\hline $3^{\text {rd }}$ tertile $(>100)$ & $5.5(\%)$ & 1 & Reference \\
\hline \multicolumn{4}{|c|}{$\mathrm{FEV}_{1}(\%$ of theoretical value $)$} \\
\hline $1^{\text {st }}$ tertile $(\leq 72)$ & $14.6(\%)$ & 2.02 & $1.55-2.72 *$ \\
\hline $2^{\text {nd }}$ tertile $(73-98)$ & $7.9(\%)$ & 1.33 & $0.92-1.57$ \\
\hline $3^{\text {rd }}$ tertile $(>98)$ & $6.8(\%)$ & 1 & Reference \\
\hline \multicolumn{4}{|l|}{ Atrial fibrillation } \\
\hline No & $8.7(\%)$ & 1 & Reference \\
\hline Yes & $16.6(\%)$ & 1.82 & $1.18-2.81 \dagger$ \\
\hline \multicolumn{4}{|l|}{ Left ventricular hypertrophy } \\
\hline No & $8.7(\%)$ & 1 & Reference \\
\hline Yes & $11.7(\%)$ & 1.42 & $1.01-2.02+$ \\
\hline \multicolumn{4}{|l|}{ Diabetes } \\
\hline No & $8.4(\%)$ & 1 & Reference \\
\hline Yes & $11.4(\%)$ & 1.35 & $1.02-1.78 \dagger$ \\
\hline \multicolumn{4}{|l|}{ Sodium (mmol/L) } \\
\hline $1^{\text {st }}$ tertile $(130-139)$ & $11.4(\%)$ & 1.95 & $1.44-2.63^{*}$ \\
\hline $2^{\text {nd }}$ tertile $(140-144)$ & $8.4(\%)$ & 1.34 & $0.98-1.83$ \\
\hline $3^{\text {rd }}$ tertile $(\geq 145)$ & $7(\%)$ & 1 & Reference \\
\hline
\end{tabular}

$\mathrm{FEV}_{1}=$ forced expiratory volume in 1 second $\mathrm{CI}=$ confidence interval. $* P<$ $0.00001 ; \dagger P<0.005 ; \ddagger P<0.04$. 
CHF mortality progressively increased from the first to last tertile of heart rate $(8 \%, 8.1 \%, 11.2 \%$, respectively), becoming significant $(P<0.04)$ only at the $3^{\text {rd }}$ tertile versus the $1^{\text {st }}$ tertile. In multivariate analysis, heart rate independently predicted CHF mortality; the RR sharply increased to 1.32 (95\% CI, 1.10 to 1.96 ) when it was $\geq 81 \mathrm{bpm}$.

Atrial fibrillation was diagnosed in 102 subjects at the initial screening $(3.5 \%)$. CHF mortality was higher in subjects with atrial fibrillation than in those without $(16.6 \%$ versus $8.7 \%, P<0.001)$. In multivariate analysis, atrial fibrillation strongly predicted CHF mortality with a $\chi^{2}$ of $6.4(P<0.01)$ and the RR of having atrial fibrillation was 1.82 (95\% CI, 1.18 to 2.81$)$.

Subjects with LVH had higher CHF mortality than those without (11.7\% versus $8.7 \%$, [RR]: $1.42 ; 95 \% \mathrm{CI}, 1.01$ to $2.02, P<0.04)$.

CHF mortality was significantly $(P<0.05)$ higher in diabetic patients $(11.4 \%)$ than in normoglycaemic subjects $(8.4 \%,[\mathrm{RR}]: 1.35 ; 95 \% \mathrm{CI}, 1.02$ to 1.78).

A VC $\leq 81 \%$ and $\mathrm{FEV}_{1} \leq 72 \%$ significantly increased CHF mortality ([RR]: $2.50 ; 95 \% \mathrm{CI}, 1.88$ to 3.32 , and 2.02 ; $95 \% \mathrm{CI}, 1.55$ to 2.72 , respectively).

Finally, the risk of CHF mortality after adjustment for confounding factors was significantly higher when the serum sodium level was $\leq 139 \mathrm{mmol} / \mathrm{L}$ ([RR]: 1.95 ; $95 \%$ CI, 1.44 to 2.63 ).

\section{DISCUSSION}

Although CHF is highly prevalent in the elderly, few studies have evaluated the predictors of CHF mortality in elderly subjects at a population level. Indeed, the main findings concerning $\mathrm{CHF}$ in this age class derive from studies conducted in the United States; the Framingham study, ${ }^{6}$ the Cardiovascular Health study, ${ }^{12}$ the New Haven Connecticut cohort of the Established Population for Epidemiological Studies of the Elderly program, ${ }^{13)}$ and the experiences of Cowie, et al ${ }^{10)}$ and Senni, et $a l^{20)}$ have made the greatest contribution to this topic.

In Europe, the data on CHF in the elderly derive from the Rotterdam Study ${ }^{13)}$ and in part from the non-population-based experience that Cowie, et $a l^{21)}$ reported among general practitioners of West London. As a consequence, in Europe the independent predictors of $\mathrm{CHF}$ in this age class are not well defined.

In the CASTEL, apart from age, 10 main predictors of CHF mortality were identified, namely male gender, historical CAD, atrial fibrillation, reduced VC or $\mathrm{FEV}_{1}, \mathrm{LVH}$, pulse pressure, diabetes, heart rate, and serum sodium.

The CASTEL supports the belief by Gottdiener ${ }^{12)}$ and Chen ${ }^{11)}$ that the incidence of $\mathrm{CHF}$ is associated with advanced age and male gender. Nevertheless, in our experience elderly men had a CHF mortality significantly greater than women 
only until the age of 75 years, after which there was no gender-related difference in CHF mortality. This confirms the observation that with advancing age the cardiovascular risk pattern of women becomes similar to that of men. ${ }^{22)}$

The role of historical CAD was another important predictor of CHF mortality. There is convincing evidence that prolonged episodes of myocardial ischemia lead to impairment of left ventricular function and ultimately to $\mathrm{CHF}^{23)}$ On the other hand, it has recently been demonstrated that myocardial blood flow reserve is impaired in subjects with $\mathrm{CHF}^{24)}$ Preventing the progression of CHF can be difficult as multiple risk factors contribute to the decline of cardiac function. However, as $\mathrm{CAD}$ is the most common risk factor for $\mathrm{CHF},{ }^{25)}$ preventing $\mathrm{CAD}$ may lead to the prevention of CHF progression.

In the last two decades, interest in the prognostic role of pulse pressure (PP) has increased tremendously. Many epidemiological studies have demonstrated that PP is a major predictor of cardiovascular risk in the general population, ${ }^{26,27)}$ particularly in the elderly. ${ }^{28,29)}$ The increase in PP is an age-related phenomenon ${ }^{28)}$ and an indicator of large artery stiffness ${ }^{29)}$; this last condition increases afterload $^{30)}$ and myocardial oxygen demand, impairs ventricular relaxation, and causes subendocardial ischemia even in the absence of CAD. ${ }^{31)}$ These effects make elderly people more prone to myocardial ischemia and ventricular dysfunction (ie. to CHF). ${ }^{32)}$ Nevertheless, in our experience and according to Chen, et $a l,{ }^{11)}$ the association between high PP and CHF was independent of the presence of CAD, suggesting that the pressor effects on ventricular dysfunction are mediated by other mechanisms. Further investigations will be necessary to clarify this hypothesis. It is worthy of note that CHF mortality did not depend on the level of hypertension. The categorisation into normotensive and hypertensive, certainly appropriate for middle-aged adults, is therefore not appropriate for the elderly.

The activation of the adrenergic system represents the main regulatory mechanism occurring during the development of left ventricular dysfunction. Furthermore, increased production of catecholamines in patients with CHF determines in the long run both direct damage to cardiomyocytes ${ }^{33)}$ and a negative feedback on the cardiovascular system, due to activation of the renin-angiotensin system. In the CASTEL, male subjects with a heart rate $\geq 81 \mathrm{bpm}$ were found to be at increased risk of CHF mortality, while this was not the case for women.

Atrial fibrillation (AF) is the most common arrhythmia observed in clinical practice. Although it can occur at any age, its frequency increases with increasing age. ${ }^{34)} \mathrm{CHF}$ and $\mathrm{AF}$ are often present in the same patient, and interact with each other leading to a vicious circle. In fact, CHF may cause AF via electromechanical feedback and adrenergic activation, while AF may promote CHF by increasing heart rate. ${ }^{35)}$ Our data demonstrate the role of $\mathrm{AF}$ as an independent risk factor 
for $\mathrm{CHF}$ mortality, and underline the clinical value of the simple procedure represented by taking radial pulse in elderly subjects.

LVH was found to be independently associated with an increased risk of CHF mortality even after adjustment for confounders. This is in keeping with the results of other studies. ${ }^{36,37)}$ Myocardial hypertrophy provides an effective shortterm compensation in subjects with CHF. However, in the long term, changes occur in the geometry of the myocardium, leading to left ventricular remodelling. This is accompanied by myocyte abnormalities ${ }^{38)}$ leading to ventricular arrhythmias and sudden death.

There is clear evidence that diabetes mellitus increases the prevalence and severity of CHF and worsens the prognosis of patients with $\mathrm{CHF}$, especially of those with coexisting CAD. ${ }^{39)}$ This is particularly true for elderly patients. ${ }^{40)}$ When CHF mortality was analysed in the CASTEL, the adjusted RR of diabetes was 1.35 . On the other hand, CHF is accompanied by insulin-resistance, which in turn represents the main risk factor for the development of diabetes. ${ }^{41)}$ In the CASTEL, the prevalence of diabetes was in fact higher among subjects with a history of CHF than in those without.

Chronic obstructive pulmonary disease (COPD) is very common in the elderly, and represents the fifth most common cause of death in the world. ${ }^{42)} \mathrm{FEV}_{1}$ and $\mathrm{VC}$ are the tests most widely used for the diagnosis of impaired pulmonary function, and are considered independent risk indicators for cardiovascular diseases. ${ }^{43)}$ In our study the inverse relationship between $\mathrm{FEV}_{1}$ or $\mathrm{VC}$ and CHF mortality persisted after adjustment for age; according to Kannel, et $a l^{44)}$ reduced pulmonary function therefore independently predicts CHF death. The mechanism of this association is not well established. Conversely, it has been found that pulmonary congestion produced by left ventricular failure causes both obstructive and restrictive alterations of pulmonary function leading to COPD. ${ }^{45)}$ Whatever the nature of the association between COPD and CHF mortality may be, ventilatory tests should always be taken into consideration when dealing with elderly people, to allow early identification of the subjects at greatest risk of CHF mortality.

Hyponatremia (serum sodium $\leq 139 \mathrm{mmol} / \mathrm{L}$ ) was one of the strongest predictors of CHF mortality. Madsen, et al ${ }^{46)}$ established a threshold of $137 \mathrm{mmol} / \mathrm{L}$ for increased risk of sudden death in subjects with CHF. Hyponatremia occurs as a consequence of the activation of the renin-angiotensin-aldosterone system. ${ }^{47)}$ This does not explain why hyponatremia independently predicted CHF mortality at a population level; one can only speculate that it is the expression of a subclinical form of CHF (water retention).

In conclusion, the results of this epidemiological survey - the first one in Italy to have provided data about CHF mortality in elderly people from the gen- 
eral population - indicate that $\mathrm{CHF}$ represents an important risk factor, or better, the most frequent CAD-associated cause of death. In summary, we found that CHF mortality in elderly people from the general population is mainly attributed to classic risk factors, but additional parameters (e.g. PP, heart rate, VC, $\mathrm{FEV}_{1}$, and serum sodium) have been identified in the CASTEL as independent risk factors of CHF death.

Outlining the identikit of elderly patients at increased risk for CHF will provide a reference model for the early detection of elderly subjects prone to die due to this syndrome.

\section{REFERENCES}

1. Sans S, Kesteloot H, Kromhout D. The burden of cardiovascular diseases mortality in Europe. Task Force of the European Society of Cardiology on Cardiovasculary Mortality and Morbidity Statistics in Europe. Eur Heart J 1997; 18: 1231-48.

2. US Department of Health and Human Services. Morbidity and Mortality Chartbook on Cardiovascular, Lung, and Blood Disease 1990-1994. Bethesda, MD: National Institutes of Health, National Heart, Lung and Blood Institutes; 1994.

3. Rich MW. Epidemiology, pathophysiology, and etiology of congestive heart failure in older adults. J Am Geriatr Soc 1997; 45: 968-74. (Review)

4. Mejhert M, Persson H, Edner M, Kahan T. Epidemiology of heart failure in Sweden - a national survey. Eur J Heart Fail 2001; 3: 97-103.

5. Darius H. Role of nitrates for the therapy of coronary artery disease patients in the years beyond 2000. J Cardiovasc Pharmacol 1999; 34 Suppl 2: S15-20; discussion s29-31. (Review)

6. Ho KK, Pinsky JL, Kannel WB, Levy D. The epidemiology of heart failure: the Framingham Study. J Am Coll Cardiol 1993; 22: 6A-13.

7. The SOLVD Investigators. Effect of enalapril on survival in patients with reduced left ventricular ejection fractions and congestive heart failure. The SOLVD Investigators. N Engl J Med 1991; 325: 293-302.

8. Reitsma JB, Mosterd A, de Craen AJ, et al. Increase in hospital admission rates for heart failure in The Netherlands, 1980-1993. Heart 1996; 76: 388-92.

9. Parameshwar J, Shackell MM, Richardson A, Poole-Wilson PA, Sutton GC. Prevalence of heart failure in three general practices in north west London. Br J Gen Pract 1992; 42: 287-9.

10. Cowie MR, Wood DA, Coats AJ, et al. Survival of patients with a new diagnosis of heart failure: a population based study. Heart 2000; 83: 505-10.

11. Chen YT, Vaccarino V, Williams CS, Butler J, Berkman LF, Krumholz HM. Risk factors for heart failure in the elderly: a prospective community-based study. Am J Med 1999; 106: 605-12.

12. Gottdiener JS, Arnold AM, Aurigemma GP, et al. Predictors of congestive heart failure in the elderly: the Cardiovascular Health Study. J Am Coll Cardiol 2000; 35: 1628-37.

13. Mosterd A, Cost B, Hoes AW, et al. The prognosis of heart failure in the general population: The Rotterdam Study. Eur Heart J 2001; 22: 1318-27.

14. Casiglia E, Spolaore P, Mormino P, et al. The CASTEL project (CArdiovascular STudy in ELderly): protocol, study design, and preliminary results of the initial survey. Cardiologia 1991; 36: 569-76.

15. Cherniack RM, Raber MB. Normal standards for ventilatory function using an automated wedge spirometer. Am Rev Respir Dis 1972; 106: 38-46.

16. Prineas RJ, Crow RS, Blackburn H. The Minnesota code manual of electrocardiographic findings: standards and procedures for measurement and classification. Littleton, Mass: John Wright PSG Inc; 1982. 
17. Remme WJ, Swedberg K. Task Force for the Diagnosis and Treatment of Chronic Heart Failure. European Society of Cardiology. Guidelines for the diagnosis and treatment of chronic heart failure. Eur Heart J 2001; 22 : 1527-60.

18. Cox DR. Regression models and life tables. J Roy Statist Soc 34, Series B, 1972: 187-220.

19. Cox DR, Oakes D. Analysis of Survival Data. London: Chapman and Hall; 1984.

20. Senni M, Tribouilloy CM, Rodeheffer RJ, et al. Congestive heart failure in the community: trends in incidence and survival in a 10-year period. Arch Intern Med 1999; 159: 29-34.

21. Cowie MR, Wood DA, Coats AJ, et al. Incidence and aetiology of heart failure; a population-based study. Eur Heart J 1999; 20: 421-8.

22. Mercuro G, Zoncu S, Dragoni F. Gender differences in cardiovascular risk factors. Ital Heart J 2003; 4: $363-6$. (Review)

23. van Veldhuisen DJ, van den Heuvel AF, Blanksma PK, Crijns HJ. Ischemia and left ventricular dysfunction: a reciprocal relation? J Cardiovasc Pharmacol 1998; 32 (Suppl 1): S46-S51.

24. Schocken DD. Epidemiology and risk factors for heart failure in the elderly. Clin Geriatr Med 2000; 16: 40718. (Review)

25. Go AS, Rao RK, Dauterman KW, Massie BM. A systematic review of the effects of physician specialty on the treatment of coronary disease and heart failure in the United States. Am J Med 2000; 108: 216-26.

26. Verdecchia P, Schillaci G, Borgioni C, Ciucci A, Pede S, Porcellati C. Ambulatory pulse pressure: a potent predictor of total cardiovascular risk in hypertension. Hypertension 1998; 32: 983-8.

27. Benetos A, Safar M, Rudnichi A, et al. Pulse pressure: a predictor of long-term cardiovascular mortality in a French male population. Hypertension 1997; 30: 1410-5.

28. Mazza A, Pessina AC, Gianluca P, Tikhonoff V, Pavei A, Casiglia E. Pulse pressure: an independent predictor of coronary and stroke mortality in elderly females from the general population. Blood Pressure 2001; 10: 20511.

29. Casiglia E, Mazza A, Tikhonoff V, Scarpa R, Schiavon L, Pessina AC. Total cholesterol and mortality in the elderly. J Intern Med 2003; 254: 353-62.

30. Milnor WR. Arterial impedance as ventricular afterload. Circ Res 1975; 36: 565-70.

31. Baguet JP, Mallion JM, Moreau-Gaudry A, Noirclerc M, Peoc'h M, Siche JP. Relationships between cardiovascular remodelling and the pulse pressure in never treated hypertension. J Hum Hypertens 2000; 14: 23-30.

32. Chae CU, Pfeffer MA, Glynn RJ, Mitchell GF, Taylor JO, Hennekens CH. Increased pulse pressure and risk of heart failure in the elderly. JAMA 1999; 281: 634-9.

33. Choy AM, Darbar D, Lang CC, et al. Detection of left ventricular dysfunction after acute myocardial infarction: comparison of clinical, echocardiographic, and neurohormonal methods. Br Heart J 1994; 72: 16-22.

34. Kannel WB, Abbott RD, Savage DD, McNamara PM. Epidemiologic features of chronic atrial fibrillation: the Framingham study. N Engl J Med 1982; 306: 1018-22.

35. Van den Berg MP, Tuinenburg AE, Crijns HJ, Van Gelder IC, Gosselink AT, Lie KI. Heart failure and atrial fibrillation: current concepts and controversies. Heart 1997; 77: 309-13. (Review)

36. Aronow WS, Ahn C. Association of electrocardiographic left ventricular hypertrophy with the incidence of new congestive heart failure. J Am Geriatr Soc 1998; 46: 1280-1.

37. Kannel WB, Dannenberg AL, Levy D. Population implications of electrocardiographic left ventricular hypertrophy. Am J Cardiol 1987; 60: 85I-93I.

38. Swynghedauw B. Remodelling of the heart in response to chronic mechanical overload. Eur Heart J 1989; 10: 935-43. (Review)

39. Fein FS, Sonnenblick EH. Diabetic cardiomyopathy. Prog Cardiovasc Dis 1985; 27: 255-70. (Review)

40. Kannel WB, Hjortland M, Castelli WP. Role of diabetes in congestive heart failure: the Framingham study. Am J Cardiol 1974; 34: 39-43.

41. Amato L, Paolisso G, Cacciatore F, et al. Congestive heart failure predicts the development of non-insulindependent diabetes mellitus in the elderly. The Osservatorio Geriatrico Regione Campania Group. Diabetes Metab 1997; 23: 213-8.

42. Yohannes AM, Roomi J, Waters K, Connolly MJ. Quality of life in elderly patients with COPD: measurement and predictive factors. Respir Med 1998; 92: 1231-6.

43. Beaty TH, Cohen BH, Newill CA, Menkes HA, Diamond EL, Chen CJ. Impaired pulmonary function as a risk factor for mortality. Am J Epidemiol 1982; 116: 102-13. 
44. Kannel WB, D'Agostino RB, Silbershatz. Use of vital capacity for cardiac failure risk estimation in persons with coronary disease and left ventricular hypertrophy. Am J Cardiol 1996; 77: 1155-8.

45. Ries AL, Gregoratos G, Friedman PJ, Claussen JL. Pulmonary function tests in the detection of left heart failure: correlation with pulmonary artery wedge pressure. Respiration 1986; 49: 241-50.

46. Madsen BK, Rasmussen V, Hansen JF. Predictors of sudden death and death from heart failure in patients with heart insufficiency are different. Ugeskr Laeger 1999; 161: 34-9. (Danish)

47. Elisaf M, Theodorou J, Pappas C, Siamopoulos K. Successful treatment of hyponatremia with angiotensin-converting enzyme inhibitors in patients with congestive heart failure. Cardiology 1995; 86: 477-80. 